\title{
Infection, Oxygen, and Immaturity: Interacting Risk Factors for Retinopathy of Prematurity
}

\author{
Minghua Chen ${ }^{\mathrm{a}}$ Ayse Çitil $^{\mathrm{a}}$ Frank McCabe $^{\mathrm{b}}$ Katherine M. Leicht ${ }^{\mathrm{a}}$ \\ John Fiascone ${ }^{a}$ Christiane E.L. Dammann ${ }^{\text {a,d }}$ Olaf Dammann ${ }^{\text {a, } c, e}$ \\ ${ }^{a}$ Division of Newborn Medicine, Floating Hospital for Children at Tufts Medical Center, ${ }^{b}$ Department of \\ Ophthalmology, Tufts University School of Medicine, and ' Neuroepidemiology Unit, Department of Neurology, \\ Children's Hospital, Boston, Mass., USA; ${ }^{\mathrm{d}}$ Department of Pediatric Pulmonology and Neonatology and \\ e Perinatal Neuroepidemiology Unit, Hannover Medical School, Hannover, Germany
}

\section{Key Words}

Infection - Oxygen - Gestational age $\cdot$ Risk factors •

Retinopathy of prematurity

\begin{abstract}
Background: Interactions among known risk factors for retinopathy of prematurity (ROP) remain to be clarified. Objectives: The aim of this study was to identify risk factors associated with ROP and to explore the interrelationships between prominent risk factors for ROP. Methods: From an institutional cohort of 1,646 very preterm newborns with gestational age $<30$ weeks or birth weight $<1,501 \mathrm{~g}$, we selected infants with a gestational age $<30$ weeks who met the criteria for ROP screening $(n=622)$ for a nested case-control analysis. Results: Of the 622 eligible newborns, 293 (47\%) were diagnosed with ROP. From multivariable analyses, gestational age $<26$ weeks (OR 2.9, $\mathrm{Cl} 1.7-4.9$ ), oxygen exposure at 28 days (OR 1.7, Cl 1.0-2.7), and neonatal sepsis (OR 2.1, Cl 1.43.2) emerged as prominent risk factors for ROP. Oxygenassociated ROP risk was more prominent among infants of 23-25 weeks' gestational age, while infection-associated ROP risk was higher among infants born at $28-29$ weeks. The OR for the joint effect of all 3 risk factors (23.5) was higher than would have been expected under the additive (8.6)
\end{abstract}

and the multiplicative (16.5) patterns of interaction. Conclusions: Our study suggests that neonatal sepsis, oxygen exposure, and low gestational age are not only independently associated with a significantly increased risk of ROP, but also interact beyond additive and even multiplicative patterns.

Copyright $\odot 2010$ S. Karger AG, Basel

\section{Introduction}

Retinopathy of prematurity (ROP) is a disorder of the developing retina [1] and an important and potentially preventable cause of blindness in childhood [2]. Although treatment options are available [3], the prevention of ROP is highly desirable. It is widely acknowledged that ROP is a multi-factorial disorder, with low gestational age, low birth weight, oxygen exposure [4-8], neonatal sepsis [911], and bronchopulmonary dysplasia [12] being important risk factors. Some of the risk factors appear to contribute to ROP by affecting the systemic cytokine and growth factor milieu [13-15].

M.C. and A.Ç. contributed equally to this work.

\section{KARGER}

두 2010 S. Karger AG, Basel

Fax +41613061234 E-Mail karger@karger.ch www.karger.com www.karger.com/neo
Minghua Chen, MD, MPH

Division of Newborn Medicine, Box 854

Floating Hospital for Children at Tufts Medical Center, 800 Washington St. Boston, MA 02111-1526 (USA)

Tel. +1 617636 7279, Fax +1 617636 3309, E-Mail mchen4@tuftsmedicalcenter.org 
It has long been suggested that risk factors may interact with each other [16]. Interaction is an important concept in biostatistics [17] and epidemiology [18], where it is also known as 'effect modification' [19]. The central idea is that exposure to one risk factor alters the impact of second or third risk factors. However, interaction studies of ROP etiology are sparse $[20,21]$.

We recently hypothesized that immaturity and inflammation-associated risk factors of ROP interact with each other [22]. In this paper, we attempt to identify risk factors associated with ROP and elucidate potential interactions.

\section{Methods}

\section{Patients}

The parent cohort from which our study population was drawn consisted of 1,646 preterm infants who were born at $<30$ weeks' gestational age or had a birth weight $<1,501 \mathrm{~g}$ and were admitted to the neonatal intensive care unit at the Floating Hospital for Children at Tufts Medical Center (Boston, Mass., USA) during the years 1997-2007. Using our local database for research purposes was approved by the Institutional Review Board of Tufts Medical Center.

Clinical data were collected for submission to the Vermont Oxford Network using their data collection forms. The clinical definitions of demographic characteristics, treatment, and outcome measures are published in current [23] and previous manuals of operations. The definition of oxygen at day 28 was the receipt of any supplemental oxygen on the 28th postnatal day. Early and late bacterial sepsis was defined as a bacterial pathogen recovered from a blood and/or cerebrospinal fluid culture obtained on day 1, 2, or 3 of life, or thereafter, respectively. Coagulase-negative Staphylococcus was defined by the presence of all 3 of the following characteristics: (1) a positive blood culture obtained from either a central line or peripheral blood sample and/ or recovered from cerebrospinal fluid obtained by lumbar puncture, ventricular tap, or ventricular drain, (2) signs of generalized infection (such as apnea, temperature instability, feeding intolerance, worsening respiratory distress, or hemodynamic instability), and (3) treatment with intravenous antibiotics for $\geq 5$ days after the above cultures were obtained [24]. As per the Vermont Oxford Network protocol, 'if the infant died, was discharged, or transferred prior to the completion of 5 days of intravenous antibiotics, this condition would still be met if the intention were to treat for 5 or more days' [24]. Fungal sepsis was defined as a fungus recovered from a blood culture obtained from either a central line or peripheral blood sample after day 3 of life. Any sepsis was defined as sepsis including any of the pathogens mentioned above.

ROP screening was performed by two attending retinal specialists from 1998 to 2007. These same attending specialists performed the laser treatment. Prior to 1998, the infants were screened by retinal fellows with supervision by attending staff. All lasers were staffed by an attending physician. The stages of ROP were classified according to the International Classification of
Retinopathy of Prematurity $[25,26]$. The ROP stage noted in our database was the highest stage clinically recorded.

We excluded infants who died in the delivery room. We did not exclude 14 infants with non-ocular congenital anomalies. Of these 14 children, 7 were cases (i.e. had ROP) and 7 were controls (i.e. did not have ROP). From the case-control perspective, $2.4 \%$ $(n=7)$ of the cases and $2.1 \%(n=7)$ of the controls had a nonocular congenital anomaly. Since these anomalies appear to be unrelated to ROP status, we felt comfortable including these 14 children in our analyses.

A total of 736 infants met the American Academy of Pediatrics criteria for ROP screening and remained in the neonatal intensive care unit for longer than 4-6 weeks' postnatal age, the time point recommended by these criteria for screening [27-29]. In order to avoid the potential biases associated with a sample definition based on birth weight [30], we restricted our sample to 622 infants with a gestational age $<30$ weeks. Two hundred and ninety-three (47\%) babies were diagnosed with ROP (cases) and were compared with 329 infants without ROP (controls).

\section{Data Analysis}

We used the Statistical Analysis Software (SAS 9.1) to create logistic regression models that yield odds ratios (OR) and 95\% CI. After initial exploratory analyses, we focused on 3 variables: low gestational age ( $<26$ weeks), oxygen exposure (operationalized as exposure to oxygen at 28 postnatal days), and any neonatal sepsis (including early bacterial sepsis, late bacterial sepsis, coagulasenegative Staphylococcus infection, and fungal sepsis). OR for combinations of these variables were calculated to identify interactions among them [31].

The most parsimonious model was built by stepwise deletion of independent variables in decreasing order of their $p$ values. All variables from table 1 were included as a starting point, except oxygen at 36 weeks' postmenstrual age (PMA), early sepsis, and late sepsis. Since information on oxygen exposure at 36 weeks' PMA was missing for more than half of the cohort due to transfer to home or to another unit before 36 weeks' PMA, we created a variable for missing information on oxygen exposure at 36 weeks' PMA. Early and any late sepsis obviously overlap with 'any sepsis' and were not included in the multivariable model to avoid collinearity. Variables were retained in the adjusted model if they were significant at $\mathrm{p}<0.05$. A process of refitting was performed to facilitate the identification of potential collinearity or confounding among the predictors. We checked model fit with HosmerLemeshow's goodness-of-fit statistic. The final model included variables that were significantly associated with ROP $(p<0.05)$ and their confounders, i.e. variables that changed the $\beta$-coefficient of $\geq 1$ covariable in the final model by $\geq 10 \%$.

Three-way interactions between the association of low gestational age, oxygen exposure, and any sepsis were evaluated using the Bartlett test for $2 \times 2 \times 2$ tables [32]. Some cells in this scenario might have small numbers with $\mathrm{n}<5$. The Bartlett test was designed to accommodate exactly this situation. Any cell with $\mathrm{n}<5$ works well in the Bartlett test (as it does in Fisher's exact test, for example).

Stratified analysis based on gestational age categories was used to explore the relationship between ROP and oxygen or infection exposure. Homogeneity of the OR was assessed using the BreslowDay test for stratified analysis. 
Table 1. Infant characteristics

\begin{tabular}{|c|c|c|c|c|}
\hline & \multicolumn{2}{|c|}{ Retinopathy of prematurity } & \multicolumn{2}{|l|}{ OR and $95 \% \mathrm{CI}$} \\
\hline & $\begin{array}{l}\text { yes } \\
(n=293)\end{array}$ & $\begin{array}{l}\text { no } \\
(\mathrm{n}=329)\end{array}$ & crude & $\begin{array}{l}\text { adjusted for } \\
\text { gestational age } \\
<26 \text { weeks }\end{array}$ \\
\hline Birth weight $<1,000 \mathrm{~g}$ (mean) & $79(835 \mathrm{~g})$ & $48(1,016 \mathrm{~g})$ & $4.0(2.8-5.7)$ & $2.3(1.6-3.4)$ \\
\hline Gestational age $<26$ weeks (mean) & 42 (25.8 weeks) & 9 (27.4 weeks) & $7.1(4.6-11.0)$ & - \\
\hline Male & 53 & 56 & $0.9(0.6-1.2)$ & $0.9(0.6-1.2)$ \\
\hline Multiple birth & 36 & 29 & $1.4(1.0-1.9)$ & $1.8(1.3-2.6)$ \\
\hline Outborn & 12 & 16 & $0.7(0.4-1.1)$ & $0.6(0.4-1.0)$ \\
\hline Hispanic & 14 & 19 & $0.7(0.5-1.1)$ & $0.6(0.4-1.0)$ \\
\hline \multicolumn{5}{|l|}{ Race } \\
\hline Black & 15 & 15 & $1.0(0.6-1.5)$ & $0.8(0.5-1.4)$ \\
\hline White & 78 & 75 & $1.2(0.8-1.8)$ & $1.3(0.9-2.0)$ \\
\hline Other & 7 & 10 & $0.7(0.4-1.2)$ & $0.7(0.4-1.3)$ \\
\hline Prenatal care & 99 & 98 & $2.4(0.6-9.2)$ & $3.0(0.7-13.2)$ \\
\hline Early bacterial sepsis & 3 & 0.3 & $9.2(1.1-74)$ & $9.9(1.2-83.4)$ \\
\hline Late bacterial sepsis & 22 & 11 & $2.3(1.5-3.7)$ & $2.0(1.3-3.3)$ \\
\hline Coagulase-negative Staphylococcus & 25 & 12 & $2.4(1.6-3.7)$ & $1.9(1.2-3.0)$ \\
\hline Late sepsis & 42 & 21 & $2.6(1.9-3.8)$ & $2.2(1.5-3.2)$ \\
\hline Fungal sepsis & 8 & 2 & $4.4(1.7-10.9)$ & $3.3(1.3-8.9)$ \\
\hline Any sepsis & 44 & 22 & $2.8(2.0-4.0)$ & $2.3(1.5-3.2)$ \\
\hline Necrotizing enterocolitis & 13 & 11 & $1.2(0.7-2.0)$ & $1.3(0.7-2.1)$ \\
\hline Ventilation & 98 & 91 & $4.8(2.0-11.7)$ & $3.0(1.2-7.5)$ \\
\hline High-frequency ventilation & 48 & 20 & $3.6(2.5-5.2)$ & $2.3(1.6-3.4)$ \\
\hline Oxygen at day 28 & 87 & 65 & $3.6(2.4-5.3)$ & $2.4(1.6-3.7)$ \\
\hline Oxygen at 36 weeks' PMA & 54 & 31 & $2.6(1.7-4.0)$ & $2.1(1.3-3.3)$ \\
\hline \multicolumn{5}{|l|}{ Oxygen at 36 weeks' PMA } \\
\hline missing data & 20 & 54 & $0.3(0.2-0.5)$ & $0.3(0.2-0.4)$ \\
\hline Respiratory distress syndrome & 98 & 91 & $5.8(2.2-15.1)$ & $4.0(1.5-10.7)$ \\
\hline Pneumothorax & 10 & 5 & $2.3(1.2-4.4)$ & $1.7(0.9-3.5)$ \\
\hline Antenatal steroid & 91 & 88 & $1.4(0.8-2.3)$ & $1.3(0.7-2.2)$ \\
\hline Postnatal steroid & 27 & 13 & $2.6(1.7-3.9)$ & $1.7(1.1-2.7)$ \\
\hline Patent ductus arteriosus & 54 & 29 & $2.8(2.0-3.8)$ & $2.0(1.4-2.9)$ \\
\hline Duct ligation & 13 & 5 & $2.8(1.5-5.2)$ & $1.5(0.8-2.9)$ \\
\hline Indomethacin & 43 & 22 & $2.6(1.9-3.7)$ & $2.0(1.3-2.9)$ \\
\hline Surfactant at any time & 97 & 89 & $3.6(1.8-7.3)$ & $2.7(1.3-5.6)$ \\
\hline Intraventricular hemorrhage (any) & 153 & 139 & $1.5(1.1-2.0)$ & $1.4(0.9-2.0)$ \\
\hline
\end{tabular}

\section{Results}

Of the 293 infants with ROP, 125 (43\%) were diagnosed with stage $1,76(26 \%)$ with stage $2,83(28 \%)$ with stage 3 , and $9(3 \%)$ with stage 4 ROP. No child in this cohort had stage 5 ROP.

\section{Univariable Analysis (table 1)}

Newborns diagnosed with ROP were more likely than controls to have a birth weight $<1,000 \mathrm{~g}$ and a gestational age $<26$ weeks. The impact of birth weight $<1,000$ g persisted when controlling for gestational age
$<26$ weeks (OR 2.3, CI 1.6-3.4). Multiple birth was associated with a two-fold increased risk for ROP (OR 1.8, CI 1.3-2.6). Gender, Hispanic ethnicity, outborn status, prenatal care and vaginal delivery were not associated with ROP.

Among infants with ROP, early sepsis, late bacterial sepsis, coagulase-negative staphylococcal infection, fungal sepsis and any sepsis were observed more frequently than in the control group. We did not find an association between necrotizing enterocolitis and ROP.

Infants with ROP were much more likely than controls to have received respiratory support and to be exposed to 
Table 2. Multivariable logistic regression model predicting any ROP with confounders

\begin{tabular}{llr}
\hline Variables & OR and 95\% CI & p value \\
\hline Birth weight $<1,000 \mathrm{~g}$ & $2.2(1.4-3.4)$ & 0.0003 \\
Gestational age $<26$ weeks & $2.9(1.7-4.9)$ & $<0.0001$ \\
Multiple birth & $2.1(1.4-3.2)$ & 0.0004 \\
Any sepsis & $2.1(1.4-3.2)$ & 0.0003 \\
High-frequency ventilation & $1.7(1.1-2.6)$ & 0.0106 \\
Oxygen at 28 days & $1.7(1.0-2.7)$ & 0.0347 \\
Patent ductus arteriosus & $1.7(1.1-2.5)$ & 0.0104 \\
Black & $1.2(0.7-2.1)$ & 0.4676 \\
Other race & $0.8(0.4-1.5)$ & 0.4399 \\
White & ref. & - \\
Years 2003-2007 & $1.0(0.7-1.5)$ & 0.9079 \\
Years 1997-2002 & ref. & - \\
\hline
\end{tabular}

oxygen at 28 days and at 36 weeks' PMA. The absence of information about oxygen at 36 weeks' PMA due to the child's discharge before this age was associated with a prominently decreased risk. Moreover, ROP cases had more patent ductus arteriosus and indomethacin treatment than controls.

After adjusting for gestational age $<26$ weeks, respiratory distress syndrome (OR 4.0, CI 1.5-10.7), mechanical ventilation (OR 3.0, CI 1.2-7.5), and the need for high frequency ventilation (OR 2.3, CI 1.6-3.4) were strongly associated with ROP. Both oxygen at 28 postnatal days and oxygen at 36 weeks' PMA were significantly associated with ROP (OR 2.4, CI 1.6-3.7 and OR 2.0, CI 1.3-3.3, respectively).

Postnatal steroid use was associated with a two-fold increased risk of ROP (OR 1.7, CI 1.1-2.7), while patent ductus arteriosus and indomethacin were associated with a two-fold increase in the risk of ROP (OR 2.0, CI 1.4-2.9 and OR 2.0, CI 1.3-2.9, respectively). Surfactant use at any time was associated with a three-fold increased risk of ROP (OR 2.7, CI 1.3-5.6). We found no significant association between pneumothorax, duct ligation and antenatal steroid use and ROP. Intraventricular hemorrhage was associated with ROP at the univariable level, but not when adjusted for gestational age.

\section{Multivariable Analysis (table 2)}

Twenty-seven variables served as a starting point for our most parsimonious model for ROP that included only significant factors for ROP (any grade). The final model retained birth weight $<1,000$ g, gestational age $<26$ weeks, multiple birth, any sepsis, high-frequency ventilation, oxygen at day 28 and patent ductus arteriosus as significant predictors, with race as a confounder.

\section{Interaction (table 3)}

We looked at all possible combinations of the 3 risk factors gestational age $<26$ weeks, oxygen exposure at 28 days, and sepsis in comparison to infants who were not exposed to any of the three. The observed OR for the joint effect of all 3 risk factors (23.5) was considerably higher than expected under the additive (8.6) and multiplicative pattern (16.5) of interaction.

An examination of each of the two-factor interactions showed that the joint effect of gestational age $<26$ weeks and oxygen exposure was significantly higher than would have been expected under the multiplicative model (16.4 compared to 3.9). The joint effect of gestational age $<26$ weeks and any sepsis was higher than the expected multiplicative model (8.6 compared to 6.6). The joint effect of oxygen exposure and any sepsis was much lower than expected under the multiplicative model (5.0 compared to 11.8). Hence, the main sub-multiplicative interaction appeared to be the two-way interaction between gestational age $<26$ weeks and oxygen exposure $(\mathrm{p}<0.0001)$, with the sub-multiplicative interaction between gestational age $<26$ weeks and any sepsis $(\mathrm{p}=0.0149)$ also contributing significantly.

\section{Stratified Analysis (table 4)}

In stratified analyses, oxygen exposure was associated with a six-fold increased risk of ROP $(5.9,1.3-28.3)$ in infants with a gestational age $<26$ weeks, but with a less prominent risk increase in older gestational age strata (26-27 weeks: OR 1.5, CI 0.8-2.8; 28-29 weeks: OR 1.9, CI 0.9-3.9). Conversely, any sepsis was associated with a 4.5 -fold risk increase for ROP among infants $>27$ weeks' gestation, but not in those 23-27 weeks' gestation.

\section{'Multi-Hit' Analysis}

When displayed by the presence or absence of low gestational age $(<26$ weeks), any sepsis, and oxygen exposure, fully $85 \%$ (95\% CI for proportion $74-92 \%$ ) of the newborns in our database who had all 3 'hits' had a ROP diagnosis (fig. 1). Only 19\% (13-27\%) of the newborns without any of these factors had ROP. Among the 3 factors, gestational age had the most prominent effect for ROP occurrence and progression. The incidence of highgrade ROP tended to decrease with exposure to a decreasing number of these 3 risk factors. 
Table 3. Three-way interaction of low gestational age, oxygen at 28 neonatal days, and any sepsis for ROP

\begin{tabular}{|c|c|c|c|c|c|c|c|c|c|}
\hline \multirow[t]{2}{*}{ Group } & \multirow{2}{*}{$\begin{array}{l}\text { Gestational } \\
\text { age }<26 \text { weeks }\end{array}$} & \multirow{2}{*}{$\begin{array}{l}\text { Oxygen at } \\
28 \text { days }\end{array}$} & \multirow{2}{*}{$\begin{array}{l}\text { Any } \\
\text { sepsis }\end{array}$} & \multicolumn{3}{|l|}{ ROP } & \multirow{2}{*}{$\begin{array}{l}\text { Bartlett } \\
\text { interaction test } \\
\text { p value }\end{array}$} & \multirow{2}{*}{$\begin{array}{l}\text { Expected OR } \\
\text { under multipli- } \\
\text { cative assumption }\end{array}$} & \multirow[t]{2}{*}{$\mathrm{OR}^{1}$} \\
\hline & & & & yes, $n$ & no, $\mathrm{n}$ & yes, $\%$ & & & \\
\hline 1 & + & + & + & 60 & 11 & 85 & 0.46 & 16.5 & 23.5 \\
\hline 2 & + & + & - & 61 & 16 & 79 & $<0.0001$ & 3.9 & 16.4 \\
\hline 3 & + & - & + & 2 & 1 & 67 & 0.0149 & 6.6 & 8.6 \\
\hline 4 & + & - & - & 1 & 3 & 25 & & & 1.4 \\
\hline 5 & - & + & + & 53 & 46 & 54 & 0.22 & 11.8 & 5.0 \\
\hline 6 & - & + & - & 79 & 137 & 37 & & & 2.5 \\
\hline 7 & - & - & + & 13 & 12 & 52 & & & 4.7 \\
\hline 8 & - & - & - & 23 & 99 & 19 & & & ref. \\
\hline
\end{tabular}

${ }^{1}$ From univariate comparisons of children with one of the first 7 combinations of characteristics to infants without any of these.

\section{Discussion}

We observed prominent interaction patterns among the 3 known risk factors of ROP, low gestational age, oxygen exposure, and neonatal sepsis. This is the first report that quantifies these patterns.

Our first major finding is that we confirmed the known strong association between low gestational age, low birth weight, and ROP [33-35]. Our finding that neonatal sepsis is a significant risk factor for ROP is also in keeping with previous studies $[9,10,36,37]$. In our univariable analyses, both bacterial sepsis and fungal sepsis were associated with increased risk of ROP, confirming one meta-analysis [38] and multiple observational studies $[10,11,36]$. As expected based on received knowledge, oxygen exposure was a strong predictor of ROP.

\section{Oxygen Exposure}

Our second major finding is that oxygen exposure is more strongly associated with ROP risk among infants with the lowest gestational age than in older infants, probably because low gestational age stands in for increased vulnerability of the developing retina at lower gestational ages.

The first phase of ROP occurs from birth to PMA approximately 30-32 weeks trigged by hyperoxia [39]. Oxygen exposure in this phase suppresses vascular endothelial growth factor (VEGF) expression, resulting in the cessation of normal vessel growth and regression of existing vessels, explaining the longstanding recognition that oxygen exposure in the first few weeks of life increases the likelihood of ROP occurrence [4-6, 40-44]. Our finding that the risk of ROP in association with oxygen expo-
Table 4. Oxygen exposure at 28 days and any sepsis predicting ROP in strata defined by gestational age at birth/post-menstrual age at 28 days

\begin{tabular}{lllll}
\hline Age, weeks & & & \multicolumn{2}{l}{ OR and 95\% CI } \\
\cline { 1 - 2 } \cline { 5 - 6 } gestational & $\begin{array}{l}\text { post-menstrual } \\
\text { (at 28 days) }\end{array}$ & & $\begin{array}{l}\text { oxygen } \\
\text { at 28 days }\end{array}$ & any sepsis \\
\hline $23-25$ & $27-29$ & & $5.9(1.3-28.3)$ & $1.6(0.7-3.5)$ \\
$26-27$ & $30-31$ & & $1.5(0.8-2.8)$ & $1.7(1.01-3.0)$ \\
$28-29$ & $32-33$ & $1.9(0.9-3.9)$ & $4.5(2.2-9.3)$ \\
\hline
\end{tabular}

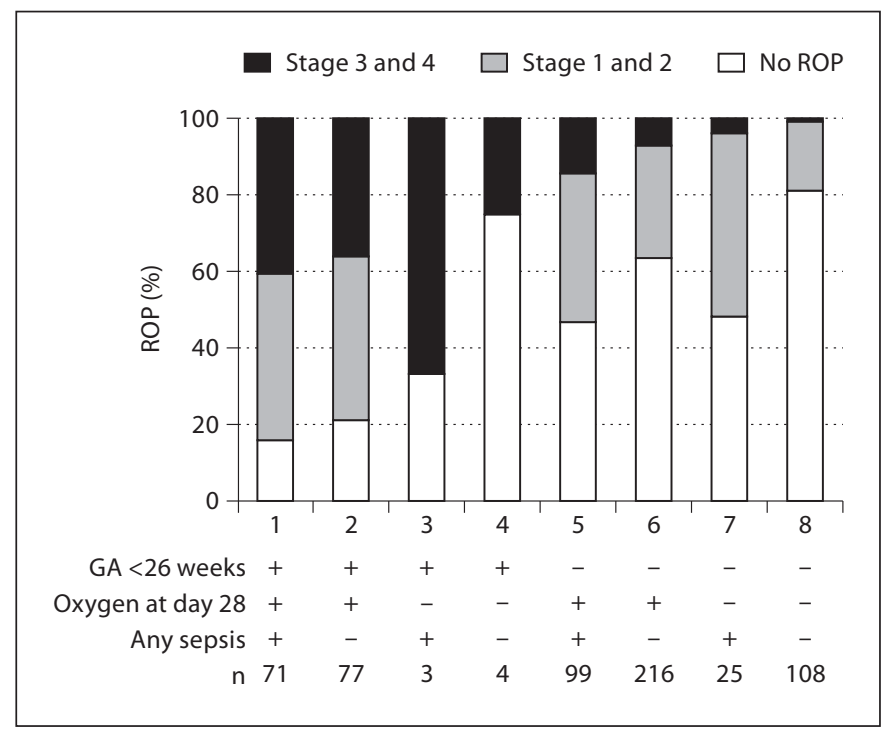

Fig. 1. Low gestational age, oxygen at 28 day, and any sepsis as risk factors in different combinations for ROP in the whole sample. 
sure at 28 days is modified by gestational age at birth (table 4) is likely to be related to the different PMA of infants at 28 days, since the gestational age plus 28 days equals the PMA at which the infant received oxygen. In our data, oxygen exposure loses its strong risk information at around 30-33 weeks' PMA (table 4).

The second phase of ROP is characterized by hypoxiainduced retinal neovascularization and begins around 32-34 weeks' PMA [39]. This raises the possibility that supplemental oxygen at this PMA range might improve retinal oxygenation and down-regulate retinal neovascularization in phase II of ROP. Randomized clinical trials and cohort studies indicated that high oxygen supplementation during the second phase of ROP has protective effects [45-49]. Indeed, the STOP-ROP trial showed that higher supplemental oxygen saturation in infants with a mean PMA of 35 weeks reduced disease progression to threshold by $28 \%$, although the $95 \%$ confidence limits of this estimate include the null (OR 0.72, CI 0.52-1.01) [46]. We recently performed a meta-analysis on this issue [50] which further supports our results reported here that a risk reduction by supplemental oxygen should probably not be expected until approximately 33 weeks' PMA. A recent study reported that low oxygen supplementation before 34 weeks' PMA and higher oxygen supplementation after 34 weeks' PMA significantly decreased the severity and incidence of ROP [51]. Unfortunately, actual oxygen concentrations for individual babies are not available in our database.

Much of our discussion revolves around the concept of a two-stage etiology of ROP. Even if this concept was unequivocally accepted, it would not need to invoke a clear-cut threshold between the two phases of ROP at a certain fixed PMA that is similar for all infants. At least part of both phases, and also the transition from the first to the second, are now attributed to the effects of VEGF [52] and insulin-like growth factor I [13, 53]. Thus, developmentally regulated differences among newborns with respect to such growth factors might help explain interindividual differences regarding the timing of the two phases of ROP, or even simpler, regarding the two biologically different mechanisms that are part of the ROP etiology at different stages of development.

\section{Infection Exposure}

Our third major finding is that sepsis yields stronger associations with ROP at higher gestational ages (table 4), probably by standing in for a reduced capability of younger infants to mount a potentially harmful inflammatory response.
Infections and sepsis are frequent complications among preterm infants [54,55], and both are associated with neurodevelopmental and vision impairment [56]. Fungal sepsis and any (non-specified) sepsis are significant risk factors in preterm newborns, both for threshold and all degrees of ROP [9-11, 20, 38, 57, 58]. In our study, the excess relative risk among individuals with both sepsis and low gestational age is greater than the product of the two factors. However, stratified analyses do not support the interpretation of increased vulnerability at lower gestational ages. To the contrary, the sepsis-associated risk of ROP is higher at older gestational ages. It is possible that the capability of mounting an inflammatory response to neonatal sepsis is developmentally regulated and that it is not the infection but the inflammation that contributes to ROP occurrence. For example, at least part of the protective effect of omega-3-polyunsaturated fatty acids in an experimental model of ROP is mediated through a down-regulation of the inflammatory cytokine tumor necrosis factor- $\alpha$ [59].

\section{Interaction}

Our fourth major finding is that the 3 risk factors (gestational age $<26$ weeks, oxygen exposure and any sepsis) have a joint effect that exceeds what would be expected if the individual effects were multiplicative (defined as the mathematical product of the potential interacting risk factors' OR). Further exploration revealed that the mainsub-multiplicative interaction appeared to be the twoway interaction between low gestational age and oxygen exposure, with the sub-multiplicative interaction between low gestational age and any sepsis also contributing significantly.

Interestingly, the co-occurrence of oxygen exposure and any sepsis was associated with a risk for ROP smaller than expected under the multiplicative assumption, indicating that either exposure might reduce the effect of the other. One possibility is that timing of oxygen administration fell into the second phase ROP for some infants exhibiting its potentially protective effects. Another possibility is that such an effect might be similar to the protection by hyperbaric oxygen from sepsis mortality via an interleukin-10-dependent mechanism in mice [60].

One major disadvantage of our study is that it is a secondary analysis of an existing single center database, designed for outcome research and quality control. Thus, the variables available to us lack the detail desirable for more thorough analyses. Also, the sample size of $n=622$ is too small to model interactions in a more elaborate fashion. The database incorporates infants who stayed in 
our neonatal intensive care unit for more than 4-6 weeks and who were assessed for ROP. Our results might be biased because we did not include infants who were transferred to other hospitals before $4-6$ weeks of age, the time of ROP screening. There were no practice changes regarding oxygen administration during the duration of the study other than a more pro-active use towards the end of the study period of high-flow nasal cannula. During the study years, the oxygen saturation target range was $92-96 \%$ with alarm limits set at 90 and $97 \%$. This policy was in effect until 2008 and this change should, therefore, not affect our sample. Otherwise, there were no new types of ventilators or ventilation techniques brought into the unit and patients were routinely extubated to nasal CPAP. In keeping with these issues, the two halves of the study period were not significantly different with regard to ROP risk (table 2).

In conclusion, our study suggests that neonatal sepsis, oxygen exposure and low gestational age are not only independently associated with a significantly increased risk for ROP, but also interact in a fashion that suggests syn- ergistic effects that go beyond additive and even multiplicative patterns between low gestational age and any sepsis. We also might have detected antagonistic effects between oxygen exposure and sepsis. Finally, we offer data in support of the notion that among very preterm infants, oxygen exposure might be a more prominent risk factor at extremely low gestational ages, while infection appears to gain importance later. Future observational and intervention studies of ROP should consider such interaction patterns.

\section{Acknowledgements}

We are grateful to Dr. Lois Smith for helpful comments on this paper. The authors are supported by grants from the National Eye Institute (1R21EY019253-01; O.D.), Deutsche Forschungsgemeinschaft (Da 378/3-1; C.E.L.D.), and the Richard Saltonstall Charitable Foundation (M.C.). The sponsors have no involvement in study design, data collection, analysis and interpretation of the data, the writing of the report or the decision to submit the paper for publication.

\section{References}

1 Good WV, Hardy RJ, Dobson V, Palmer EA, Phelps DL, Quintos M, et al: The incidence and course of retinopathy of prematurity: findings from the early treatment for retinopathy of prematurity study. Pediatrics 2005; 116:15-23.

-2 Steinkuller PG, Du L, Gilbert C, Foster A, Collins ML, Coats DK: Childhood blindness. J Aapos 1999;3:26-32.

3 Clark D, Mandal K: Treatment of retinopathy of prematurity. Early Hum Dev 2008;84: 95-99.

4 Kinsey VE, Arnold HJ, Kalina RE, Stern L, Stahlman M, Odell G, et al: $\mathrm{PaO}_{2}$ levels and retrolental fibroplasia: a report of the cooperative study. Pediatrics 1977;60:655-668.

$\checkmark 5$ Patz A, Hoeck LE, De La Cruz E: Studies on the effect of high oxygen administration in retrolental fibroplasia. I. Nursery observations. Am J Ophthalmol 1952;35:1248-1253.

$\checkmark 6$ Tin W, Milligan DW, Pennefather P, Hey E: Pulse oximetry, severe retinopathy, and outcome at one year in babies of less than 28 weeks gestation. Arch Dis Child Fetal Neonatal Ed 2001;84:F106-F110.

7 Anderson CG, Benitz WE, Madan A: Retinopathy of prematurity and pulse oximetry: a national survey of recent practices. J Perinatol 2004;24:164-168.

8 Ashton N, Ward B, Serpell G: Role of oxygen in the genesis of retrolental fibroplasia; a preliminary report. Br J Ophthalmol 1953;37: 513-520.
9 Maheshwari R, Kumar H, Paul VK, Singh M, Deorari AK, Tiwari HK: Incidence and risk factors of retinopathy of prematurity in a tertiary care newborn unit in New Delhi. Natl Med J India 1996;9:211-214.

$>10$ Liu PM, Fang PC, Huang CB, Kou HK, Chung MY, Yang YH, et al: Risk factors of retinopathy of prematurity in premature infants weighing less than $1600 \mathrm{~g}$. Am J Perinatol 2005;22:115-120.

-11 Manzoni P, Maestri A, Leonessa M, Mostert M, Farina D, Gomirato G: Fungal and bacterial sepsis and threshold ROP in preterm very low birth weight neonates. J Perinatol 2006;26:23-30.

-12 Holmstrom G, Broberger U, Thomassen P. Neonatal risk factors for retinopathy of prematurity - a population-based study. Acta Ophthalmol Scand 1998;76:204-207.

-13 Hellstrom A, Perruzzi C, Ju M, Engstrom E, Hard AL, Liu JL, et al: Low IGF-I suppresses VEGF-survival signaling in retinal endothelial cells: direct correlation with clinical retinopathy of prematurity. Proc Natl Acad Sci USA 2001;98:5804-5808.

14 Dordelmann M, KerkJ, Dressler F, Brinkhaus MJ, Bartels DB, Dammann CE, et al: Interleukin-10 high producer allele and ultrasound-defined periventricular white matter abnormalities in preterm infants: a preliminary study. Neuropediatrics 2006;37:130136.
15 Sarlos S, Rizkalla B, Moravski CJ, Cao Z, Cooper ME, Wilkinson-Berka JL: Retinal angiogenesis is mediated by an interaction between the angiotensin type 2 receptor, VEGF, and angiopoietin. Am J Pathol 2003; 163:879-887.

16 Lucey JF, Dangman B: A reexamination of the role of oxygen in retrolental fibroplasia. Pediatrics 1984;73:82-96.

$\checkmark 17$ Berrington De Gonzalez A, Cox DR: Interpretation of interaction: a review. Ann Appl Stat 2007;1:371-385.

18 Kenneth Rothman SG: Modern Epidemiology. Philadelphia, Lippincott Williams \& Wilkins, 1998.

19 Aschengrau A, Seage GR: Essentials of Epidemiology in Public Health. Sudbury, Jones and Bartlett, 2003.

-20 Noyola DE, Bohra L, Paysse EA, Fernandez M, Coats DK: Association of candidemia and retinopathy of prematurity in very low birthweight infants. Ophthalmology 2002;109: 80-84.

21 Karlowicz MG, Giannone PJ, Pestian J, Morrow AL, Shults J: Does candidemia predict threshold retinopathy of prematurity in extremely low birth weight $(</=1000 \mathrm{~g})$ neonates? Pediatrics 2000;105:1036-1040.

-22 Dammann O, Brinkhaus MJ, Bartels DB, Dordelmann M, Dressler F, Kerk J, et al: Immaturity, perinatal inflammation, and retinopathy of prematurity: a multi-hit hypothesis. Early Hum Dev 2009;85:325-329. 
23 Vermont Oxford Network: Manual of operations (for infants born in 2008: release 12.1 2000). Burlington, Vermont, 2008. www. vtoxford.org/home.aspx?p=/tools/downloads.htm.

24 Payne NR, Carpenter JH, Badger GJ, Horbar JD, Rogowski J: Marginal increase in cost and excess length of stay associated with nosocomial bloodstream infections in surviving very low birth weight infants. Pediatrics 2004;114:348-355.

25 International Committee for the Classification of Retinopathy of Prematurity: The International Classification of Retinopathy of Prematurity revisited. Arch Ophthalmol 2005;123:991-999.

-26 An international classification of retinopathy of prematurity. Pediatrics 1984;74:127133

-27 Screening examination of premature infants for retinopathy of prematurity. A joint statement of the American Academy of Pediatrics, the American Association for Pediatric Ophthalmology and Strabismus, and the American Academy of Ophthalmology. Pediatrics 1997;100:273.

$\checkmark 28$ American Academy of Pediatrics. Section on Ophthalmology: Screening examination of premature infants for retinopathy of prematurity. Pediatrics 2001;108:809-811.

-29 Section on Ophthalmology American Academy of Pediatrics, American Academy of Ophthalmology, American Association for Pediatric Ophthalmology and Strabismus: Screening examination of premature infants for retinopathy of prematurity. Pediatrics 2006;117:572-576, erratum in: Pediatrics 2006; $118: 1324$.

-30 Arnold CC, Kramer MS, Hobbs CA, McLean FH, Usher RH: Very low birth weight: a problematic cohort for epidemiologic studies of very small or immature neonates. Am J Epidemiol 1991;134:604-613.

31 Khoury M: Modern Epidemiology, ed 2. Philadelphia, Lippincott Williams \& Wilkins, 1998.

32 Bartlett MS: Contingency table interaction. J R Stat Soc 1935;(suppl 2):248-252.

-33 Kim TI, Sohn J, Pi SY, Yoon YH: Postnatal risk factors of retinopathy of prematurity. Paediatr Perinat Epidemiol 2004;18:130134.

34 Seiberth V, Linderkamp O: Risk factors in retinopathy of prematurity: a multivariate statistical analysis. Ophthalmologica 2000; 214:131-135.

-35 Brown BA, Thach AB, Song JC, Marx JL, Kwun RC, Frambach DA: Retinopathy of prematurity: evaluation of risk factors. Int Ophthalmol 1998;22:279-283.
36 Chye JK, Lim CT, Leong HL, Wong PK: Retinopathy of prematurity in very low birth weight infants. Ann Acad Med Singapore 1999;28:193-198.

- 37 Gunn TR, Easdown J, Outerbridge EW, Aranda JV: Risk factors in retrolental fibroplasia. Pediatrics 1980;65:1096-1100.

38 Bharwani SK, Dhanireddy R: Systemic fungal infection is associated with the development of retinopathy of prematurity in very low birth weight infants: a meta-review. J Perinatol 2008;28:61-66.

39 Chen J, Smith LE: Retinopathy of prematurity. Angiogenesis 2007;10:133-140.

40 Flynn JT, Bancalari E, Snyder ES, Goldberg RN, Feuer W, Cassady J, et al: A cohort study of transcutaneous oxygen tension and the incidence and severity of retinopathy of prematurity. N Engl J Med 1992;326:1050-1054.

41 Wright KW, Sami D, Thompson L, Ramanathan R, Joseph R, Farzavandi S: A physiologic reduced oxygen protocol decreases the incidence of threshold retinopathy of prematurity. Trans Am Ophthalmol Soc 2006; 104:78-84.

42 Wallace DK, Veness-Meehan KA, Miller WC: Incidence of severe retinopathy of prematurity before and after a modest reduction in target oxygen saturation levels. J Aapos 2007;11:170-174.

43 Vanderveen DK, Mansfield TA, Eichenwald EC: Lower oxygen saturation alarm limits decrease the severity of retinopathy of prematurity. J Aapos 2006;10:445-448.

44 Deulofeut R, Critz A, Adams-Chapman I, Sola A: Avoiding hyperoxia in infants $<$ or $=$ $1250 \mathrm{~g}$ is associated with improved shortand long-term outcomes. J Perinatol 2006 26:700-705

45 McGregor ML, Bremer DL, Cole C, McClead RE, Phelps DL, Fellows RR, et al: Retinopathy of prematurity outcome in infants with prethreshold retinopathy of prematurity and oxygen saturation $>94 \%$ in room air: the high oxygen percentage in retinopathy of prematurity study. Pediatrics 2002;110:540 544.

46 Supplemental Therapeutic Oxygen for Prethreshold Retinopathy Of Prematurity (STOP-ROP), a randomized, controlled trial. I: primary outcomes. Pediatrics 2000;105: 295-310.

47 Gaynon MW, Stevenson DK, Sunshine P, Fleisher BE, Landers MB: Supplemental oxygen may decrease progression of prethreshold disease to threshold retinopathy of prematurity. J Perinatol 1997;17:434-438.
48 Askie LM, Henderson-Smart DJ, Irwig L, Simpson JM: Oxygen-saturation targets and outcomes in extremely preterm infants. $\mathrm{N}$ Engl J Med 2003;349:959-967.

49 Seiberth V LO, Akkoyun-Vardarli I, Jendritza W, Voegele C: Oxygen therapy in acute retinopathy of prematurity stage 3 . Invest Ophthalmol Vis Sci 1998;39:S820.

50 Chen M, Guo L, Smith L, Dammann C, Dammann O: High or low oxygen saturation and severe retinopathy of prematurity. Pediatrics 2010;125:e1483-e1492.

-51 Sears JE, Pietz J, Sonnie C, Dolcini D, Hoppe G: A change in oxygen supplementation can decrease the incidence of retinopathy of prematurity. Ophthalmology 2009;116:513518.

-52 Pierce EA, Foley ED, Smith LE: Regulation of vascular endothelial growth factor by oxygen in a model of retinopathy of prematurity. Arch Ophthalmol 1996;114:1219-1228.

53 Hellstrom A, Carlsson B, Niklasson A, Segnestam K, Boguszewski M, de Lacerda L, et al: IGF-I is critical for normal vascularization of the human retina. J Clin Endocrinol Metab 2002;87:3413-3416.

54 Stoll BJ, Hansen N, Fanaroff AA, Wright LL, Carlo WA, Ehrenkranz RA, et al: Changes in pathogens causing early-onset sepsis in verylow-birth-weight infants. N Engl J Med 2002; 347:240-247.

- 55 Stoll BJ, Hansen N, Fanaroff AA, Wright LL, Carlo WA, Ehrenkranz RA, et al: Late-onset sepsis in very low birth weight neonates: the experience of the NICHD Neonatal Research Network. Pediatrics 2002;110:285-291.

- 56 Stoll BJ, Hansen NI, Adams-Chapman I, Fanaroff AA, Hintz SR, Vohr B, et al: Neurodevelopmental and growth impairment among extremely low-birth-weight infants with neonatal infection. JAMA 2004;292: 2357-2365.

57 Cats BP, Tan KE: Retinopathy of prematurity: review of a four-year period. Br J Ophthalmol 1985;69:500-503.

58 Hussain N, Clive J, Bhandari V: Current incidence of retinopathy of prematurity, 19891997. Pediatrics 1999;104:e26.

-59 Connor KM, SanGiovanni JP, Lofqvist C, Aderman CM, Chen J, Higuchi A, et al: Increased dietary intake of omega-3-polyunsaturated fatty acids reduces pathological retinal angiogenesis. Nat Med 2007;13:868873.

60 Buras JA, Holt D, Orlow D, Belikoff B, Pavlides S, Reenstra WR: Hyperbaric oxygen protects from sepsis mortality via an interleukin-10-dependent mechanism. Crit Care Med 2006;34:2624-2629. 